\title{
Riluzole Selective Antioxidant Effects in Cell Models Expressing Amyotrophic Lateral Sclerosis Endophenotypes
}

\author{
Gessica Sala ${ }^{1}$, Alessandro Arosio ${ }^{1}$, Elisa Conti ${ }^{1}$, Simone Beretta ${ }^{1,2}$, Christian Lunetta ${ }^{3}$, Nilo Riva ${ }^{4}$, \\ Carlo Ferrarese $^{1,2}$, Lucio Tremolizzo ${ }^{1,2}$ \\ ${ }^{1}$ Labaratory of Neurobiology, School of Medicine and Surgery and Milan Center for Neuroscience (NeuroMl), University of Milano-Bicocca, \\ Milano, ${ }^{2}$ Neurology Unit, San Gerardo Hospital, Monza, ${ }^{3}$ NEuroMuscular Omnicentre (NEMO), Fondazione Serena Onlus, ${ }^{4}$ San Raffaele \\ Scientific Institute, Milano, Italy
}

\begin{abstract}
Objective: Until recently, riluzole was the only drug licensed for amyotrophic lateral sclerosis (ALS). In spite of its efficacy, the mechanism of action remains elusive, and both blocking of glutamate release and antioxidant properties have been postulated. Here we characterized human SH-SY5Y neuroblastoma cell lines, taking advantage of their insensitivity to excitotoxic insults, in order to selectively assess the presence of a direct antioxidant effect of riluzole. Methods: SH-SY5Y cells, either parental or overexpressing the G93A SOD1 mutation, were exposed for 24 hours to the selected stimuli.

Results: Riluzole $(1-10 \mu \mathrm{M})$ was able to counteract the effects of $\mathrm{H}_{2} \mathrm{O}_{2}$ exposure $(200 \mu \mathrm{M} / 24 \mathrm{hr}$ ), limiting both cell death and whole-cell reactive oxygen species (ROS) increase. The same experiments were repeated using $\mathrm{SH}-\mathrm{SY} 5 \mathrm{Y}$ cells carrying the familial ALS-related G93A-SOD1 mutation and constitutively expressing two-fold increased whole-cell ROS levels with respect to wild-type cells: riluzole was ineffective in this paradigm. Analogously, riluzole was ineffective in preventing cell death induced by exposing SH-SY5Y cells to 3-morpholino-sydnonimine (SIN-1, $1.5 \mathrm{mM} / 24 \mathrm{hr}$ ), a reactive nitrogen species (RNS) donor.

Conclusion: Our data support a direct antioxidant action of riluzole. Furthermore, the lack of efficacy of riluzole observed in the SOD1 cell model mirrors the lack of efficacy already demonstrated in cognate mouse models of ALS, plausibly reflecting differences in the underlying pathogenic mechanisms. Finally, riluzole inefficacy against nitrosative stress might support the idea that a combined therapeutic intervention may result more effective in ALS patients, as in the case of co-administration of edaravone, a drug known to reduce RNS.
\end{abstract}

KEY WORDS: Riluzole; Amyotrophic lateral sclerosis; Antioxidants; Drug.

\section{INTRODUCTION}

Amyotrophic lateral sclerosis (ALS) is a relentless neurodegenerative disease for which no effective therapies exist. Until very recently, riluzole, [i.e., 6-(trifluoromethoxy) benzothiazol-2-amine] was the only drug licensed for ALS, delaying the time points for non invasive ventilation dependence or tracheostomy along the course of

Received: May 23, 2018/ Revised: August 7, 2018

Accepted: August 12, 2018

Address for correspondence: Lucio Tremolizzo

Labaratory of Neurobiology, School of Medicine and Surgery,

University of Milano-Bicocca, U8, Via Cadore 48 - 20900 Monza

$\mathrm{MB}$, Italy

E-mail: lucio.tremolizzo@unimib.it

ORCID: https://orcid.org/0000-0003-0473-6560 this disorder. Riluzole 100 mg/day (usually 50 mg, twice a day) prolongs median survival by few months in patients with ALS according to the conclusions of a recent Cochrane meta-analysis. ${ }^{1)}$ Uncertainties regarding the exact mechanism of action of this drug further complicate the matter and hinder the attempts of designing more potent drugs for increasing life expectancy in ALS. Riluzole specifically blocks tetrodotoxin-sensitive sodium channels reducing calcium influx and excessive glutamate receptor stimulation within the central nervous system. ${ }^{2)}$ Rather than blocking glutamate release, data show that it may increase glutamate uptake in rat spinal cord synaptosomes. ${ }^{3)}$ Direct antioxidant properties of this molecule have already been hypothesized, and riluzole attenuates oxidative stress induced by exposure to various

(ㄷ) This is an Open-Access article distributed under the terms of the Creative Commons Attribution Non-Commercial License (http://creativecommons.org/licenses/by-nc/4.0) which permits unrestricted non-commercial use, distribution, and reproduction in any medium, provided the original work is properly cited. 
oxidant agents. ${ }^{4,5)}$ However, the demonstration of a direct antioxidant effect of the drug with respect to an indirect antioxidant action due to the anti-glutamatergic properties still remains an open question. This information might be relevant for the ALS field, and may offer clues for novel therapeutic approaches. In fact, in spite of its limited efficacy, riluzole remains the only drug that is ineffective in the SOD1-ALS animal model and effective in human randomized controlled trials. ${ }^{1)}$ Interestingly, the recently US Food and Drug Administration-approved drug for ALS edaravone is able to reduce cerebrospinal fluid (CSF) 3-nitrotyrosine (3NT) levels in ALS patients, ${ }^{6}$ again reinforcing the idea that scavenging strategies-in this case against markers of nitrosative stress - might delay the disease course in ALS patients. ${ }^{7)}$

In this work, we used human SH-SY5Y neuroblastoma cell lines: possibly, other cell models could hold higher face, or even predictive validity when thinking to test riluzole effects. Nevertheless, we specifically chose this cell model in order to take advantage of its insensitivity to excitotoxic insults. This offered the unique opportunity ofselectively-assessing any direct effect of riluzole against ALS-related acute and chronic oxidative insults. Finally, a known acute nitrosative stress paradigm, i.e., 3-morpholino-sydnonimine (SIN-1) exposure, was tested as well. ${ }^{8)}$

\section{METHODS}

\section{Cell Cultures}

Human SH-SY5Y neuroblastoma cells, either parental, or constitutively expressing the G93A SOD1 mutation were cultured, as previously described. ${ }^{9)}$ Initial experiments were performed for testing the sensitivity of parental SH-SY5Y neuroblastoma cells to excitotoxic insults. Cells were exposed for 24 hours to glutamate (concentration range, 10 to 5,000 $\mu \mathrm{M}$ ), N-methyl-D-aspartate (concentration range, 100 to $1,000 \mu \mathrm{M}$ ), kainic acid (concentration range, 10 to $1,000 \mu \mathrm{M}$ ). Riluzole (Sigma; concentration range, 1 to $10 \mu \mathrm{M} / 24$ hours) was incubated simultaneously to hydrogen peroxide (200 $\mu \mathrm{M} / 24$ hours) or SIN-1 (1.5 mM/24 hours).

\section{Rate of 3-(4,5-Dimethylthiazol-2-yl)-2,5- Diphenyltetrazolimium (MTT) Reduction}

Cell cultures were exposed to MTT $(0.5 \mathrm{mg} / \mathrm{ml}$ final concentration) in standard medium for 45 minutes at $37^{\circ} \mathrm{C}$ in an atmosphere of $5 \% \mathrm{CO}_{2}$ in air; after cell solubilisation in DMSO, absorbance was quantified at $570 \mathrm{~nm}$ using a microplate reader (FLUOstar Omega; BMG Labtech, Ortenberg, Germany), as previously described. ${ }^{10)}$ Optical densities were expressed as percent of vehicle-treated control cells.
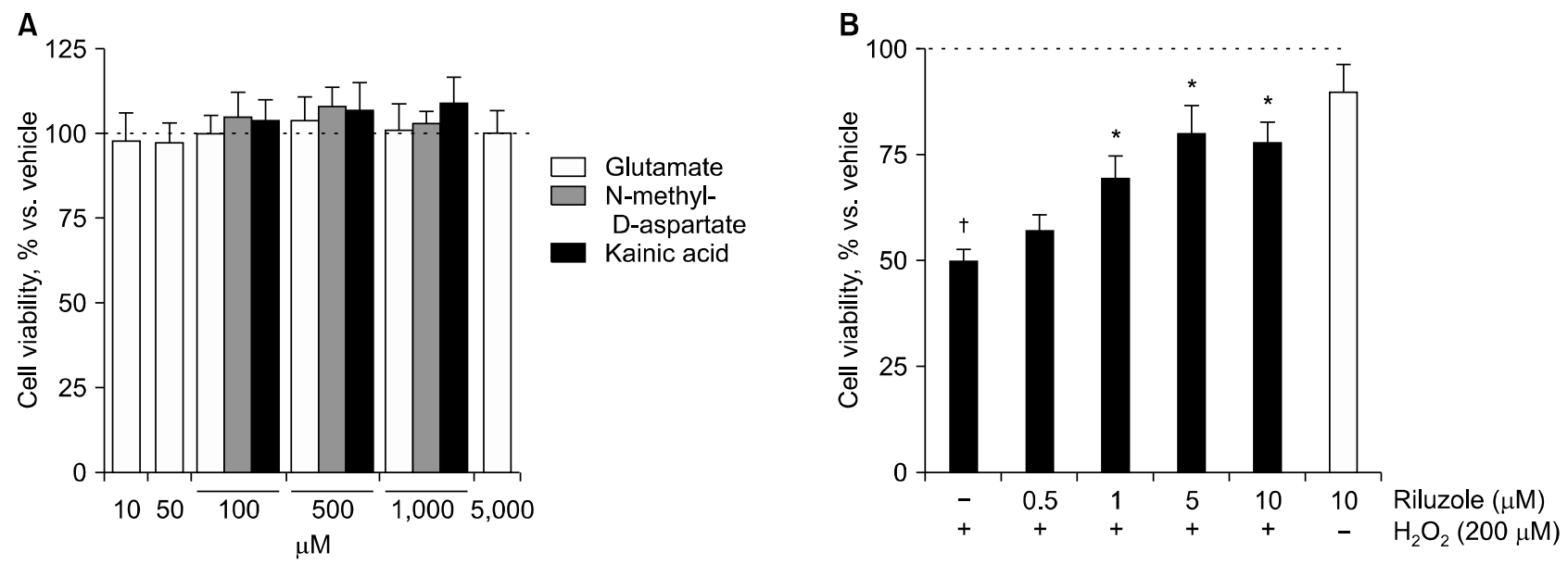

Fig. 1. (A) Excitotoxic insults (glutamate, 10-5,000 $\mu \mathrm{M} ; \mathrm{N}$-methyl-D-aspartate, 100-1,000 $\mu \mathrm{M}$; kainic acid, 100-1,000 $\mu \mathrm{M}$; exposure time, $24 \mathrm{hr}$ ) do not significantly modify cell viability in $\mathrm{SH}-\mathrm{SY} 5 \mathrm{Y}$ cells. (B) Exposure of $\mathrm{SH}-\mathrm{SY} 5 \mathrm{Y}$ cells to $\mathrm{H}_{2} \mathrm{O}_{2}(200 \mu \mathrm{M} / 24 \mathrm{hr})$ induces a $\sim 50 \%$ cell death $\left({ }^{\dagger} p<0.001\right.$ vs. vehicle-treated cells) and riluzole co-exposure $(0.5-10 \mu \mathrm{M} / 24 \mathrm{hr})$ significantly prevents $\mathrm{H}_{2} \mathrm{O}_{2}$-induced cell death $\left({ }^{*} p<0.01\right.$ vs. $\mathrm{H}_{2} \mathrm{O}_{2}$-treated cells); riluzole exposure $(10 \mu \mathrm{M})$ alone does not modify cell viability in the same cells. 


\section{Whole-cell ROS Levels}

The dye 2',7'-dichlorofluorescein diacetate (DCF-DA) was used to quantify levels of whole-cells reactive oxygen species (ROS), as previously reported. ${ }^{11)}$ Briefly, DCF-DA is de-esterified to the ionized free acid (DCFH), which reacts with ROS to form the fluorescent DCF. Cells were washed once in Locke's buffer, incubated for $\mathbf{4 5}$ minutes in $10 \mu \mathrm{M}$ DCF-DA and subsequently washed twice. Cells were collected and fluorescence was quantified using a Cary Eclipse fluorimeter (Varian, Palo Alto, CA, USA) (excitation $488 \mathrm{~nm}$, emission $525 \mathrm{~nm}$ ), after resuspension of the cell pellet in Locke's buffer containing $0.5 \%$ triton $X-100$. The values of DCF fluorescence were calculated as arbitrary fluorescence unit per $\mu$ g protein content and expressed as percent of vehicle-treated control cells.

\section{Statistical Analysis}

All results are expressed as mean \pm standard deviation. One-way ANOVA analysis of variance, followed by Tukey's multiple comparison test, was used to assess the significance of differences between values of treated versus untreated cells.

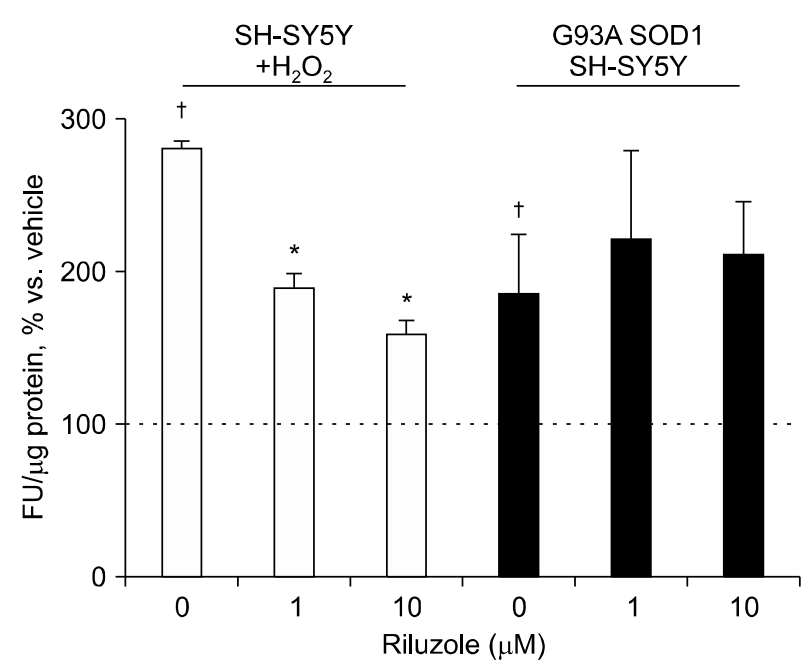

Fig. 2. Effect of riluzole exposure $(1-10 \mu \mathrm{M} / 24 \mathrm{hr})$ on $\mathrm{H}_{2} \mathrm{O}_{2}$ - induced whole-cell reactive oxygen species (ROS) production in $\mathrm{SH}-\mathrm{SY} 5 \mathrm{Y}$ cells. $\mathrm{H}_{2} \mathrm{O}_{2}(200 \mu \mathrm{M} / 24 \mathrm{hr})$ induces a about three-fold increased ROS production in $\mathrm{SH}-\mathrm{SY} 5 \mathrm{Y}$ cells (striped bars; ${ }^{\dagger} p<0.001$ vs. vehicletreated cells) and riluzole co-exposure (1-10 $\mu \mathrm{M} / 24 \mathrm{hr})$ significantly counteracts $\mathrm{H}_{2} \mathrm{O}_{2}$-induced ROS production $\left({ }^{*} p<0.05\right.$ vs. $\mathrm{H}_{2} \mathrm{O}_{2}$-treated cells); black bars show that mutant G93A SOD1 cells display under basal conditions a about two-fold increase of ROS levels with respect to parental cells $\left({ }^{\dagger} p<0.001\right)$ and that riluzole $(1-$ $10 \mu \mathrm{M} / 24 \mathrm{hr}$ ) is unable to modify this condition.

$\mathrm{FU}$, fluorescence units.

\section{RESULTS}

Human SH-SY5Y neuroblastoma cells were initially exposed to different excitotoxic insults (glutamate or $\mathrm{N}$ methyl-D-aspartate or kainic acid, in various concentrations for 24 hours; Fig. 1A) without showing signs of altered viability at the MTT assay (Fig. 1A). On the other hand, $\mathrm{H}_{2} \mathrm{O}_{2}$ exposure $(200 \mu \mathrm{M} / 24 \mathrm{hr})$ was able to significantly decrease $(\sim 50 \%)$ cell viability (Fig. 1B) and riluzole co-incubation was able to prevent the $\mathrm{H}_{2} \mathrm{O}_{2}$-induced cell death; this effect was maximal between 1 and $10 \mu \mathrm{M}$ ( $\sim 80 \%$ with respect to vehicle-treated cells, Fig. 1B). Whole-cell ROS levels were analogously increased of about three-fold following $\mathrm{H}_{2} \mathrm{O}_{2}$ exposure, and this effect was significantly, albeit not completely, prevented by riluzole exposure at the concentration of 1 and $10 \mu \mathrm{M}$ (striped bars in Fig. 2).

Exposure of SH-SY5Y cells to $1.5 \mathrm{mM} / 24 \mathrm{hr}$ SIN- 1 resulted in a $50 \% \pm 10 \%$ mortality, and riluzole 1 or $10 \mu \mathrm{M}$ failed to significantly counteract this result (Fig. 3).

In SH-SY5Y neuroblastoma cell lines carrying the G93A SOD1 mutation, no significant effect of riluzole exposure (from 0.5 to $10 \mu \mathrm{M}$ ) on cell viability was evidenced (cell viability vs. vehicle-treated cells $=97 \% \pm 6 \%$ after $10 \mu \mathrm{M}$ riluzole). Whole-cell ROS levels were constitutively expressing about two-fold higher with respect to wild-type cells (black bars in Fig. 2), as we previously reported. ${ }^{12)}$ No changes were obtained following riluzole co-incubation ( 1 and $10 \mu \mathrm{M}$; black bars in Fig. 2).

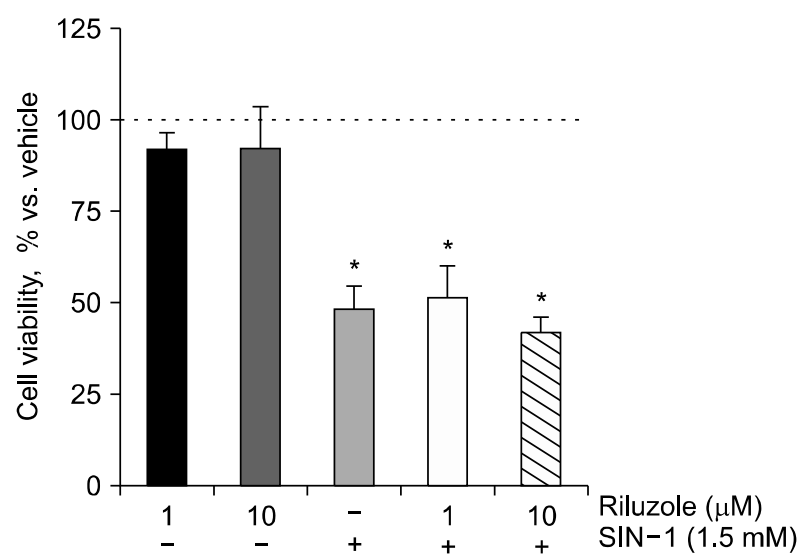

Fig. 3. Riluzole co-exposure ( 1 or $10 \mu \mathrm{M}, 24 \mathrm{hr}$ ) does not counteract $\mathrm{SIN}-1$-induced cell death in $\mathrm{SH}-\mathrm{SY} 5 Y$ cells $\left({ }^{*} p<0.05\right.$ vs. vehicletreated cells). 


\section{DISCUSSION}

ALS pathogenesis is complex and not yet completely elucidated. ${ }^{13)}$ Among the several demonstrated players, excitotoxicity (i.e., excitatory amino acid excessive stimulation) and oxidative stress dominated the early literature, showing complex and clear synergistic interactions. ${ }^{14,15)}$ Notably, this line of research led to the development of riluzole, an anti-glutamatergic compound, and until recently the only effective and licensed drug for ALS treatment. ${ }^{2)}$ Antioxidant properties of riluzole have been repeatedly shown ${ }^{4,5)}$ but there is still partial uncertainty about their direct or indirect nature, due to glutamate transmission block. Koh et al., ${ }^{4)}$ for example, nicely described the antioxidant effects of riluzole in presence of competitive or uncompetitive inhibitors of glutamate receptors. Here we initially characterized, and then took advantage of the insensitivity to excitotoxic insults of human SH-SY5Y neuroblastoma cells, not just blocking but completely removing the excitotoxic paradigm. In this experimental setting, riluzole was able to counteract $\mathrm{H}_{2} \mathrm{O}_{2}$ induced cell death and increased ROS production.

The lack of efficacy of riluzole in our nitrosative stress paradigm seems to support the hypothesis that this drug selectively targets those mechanisms leading to increased ROS production. Consequently, our findings might indirectly sustain the idea that riluzole could really express a synergistic therapeutic potential when in add-on with other drugs, such as edaravone, the newly approved compound able to reduce 3NT CSF content in treated patients. ${ }^{6}$ Previous attempts of selectively targeting nitrosative stress demonstrated that this therapeutic strategy could be, not only successful in ALS mouse models, but also effective in preventing the accumulation of abnormally phosphorylated and fragmented TDP-43 in spinal cord. ${ }^{16)}$ Furthermore, increased NO levels, spontaneously forming peroxynitrite, arise following exposure to LPS of murine microglial G93A-SOD1 cells, strictly linking nitrosative stress to the well-known ALS-involved mechanism of neuroinflammation. ${ }^{17)}$ Also, NO-dependent post-translational modifications, such as cysteine S-nitrosylation and tyrosine nitration, are linked to abnormal mitochondrial metabolism, another well-known player in ALS pathology. ${ }^{18)}$

In contrast, riluzole was uneffective in the cell model carrying the G93A SOD1 ALS-causing mutation, constitutively expressing about two-fold increased ROS pro- duction, as previously shown. ${ }^{12)}$ This is consistent with the view that an acute exposure to this drug is unable to rescue chronic oxidative damage. In any case, according to our results, riluzole has already been reported to have no significant benefit on lifespan and motor performance in SOD1 G93A transgenic mice. ${ }^{19)}$

In conclusion, we show here that riluzole demonstrates direct antioxidant defence capacities against acute oxidative, but not nitrosative stress. Furthermore, riluzole was uneffective against a chronic ALS-related paradigm, such as the expression of the SOD1 G93A mutation. This selective scavenging behaviour represents an important piece of information when thinking to novel drug design in the ALS field, since multi-drug cocktails are expected to target different players of motor neuron pathology. ${ }^{20)}$

\section{Acknowledgments}

This study was supported by UNIMIB grant \# 2017ATE-0052 (LT).

\section{- Conflicts of Interest}

No potential conflict of interest relevant to this article was reported.

\section{REFERENCES}

1. Miller RG, Mitchell JD, Moore DH. Riluzole for amyotrophic lateral sclerosis (ALS)/motor neuron disease (MND). Cochrane Database Syst Rev 2012;(3):CD001447.

2. Wokke J. Riluzole. Lancet 1996;348:795-799.

3. Azbill RD, Mu X, Springer JE. Riluzole increases high-affinity g/utamate uptake in rat spinal cord synaptosomes. Brain Res 2000;871:175-180.

4. Koh JY, Kim DK, Hwang JY, Kim YH, Seo JH. Antioxidative and proapoptotic effects of riluzole on cultured cortical neurons. J Neurochem 1999;72:716-723.

5. Storch A, Burkhardt K, Ludolph AC, Schwarz J. Protective effects of riluzole on dopamine neurons: involvement of oxidative stress and cellular energy metabolism. I Neurochem 2000;75:2259-2269.

6. Yoshino H, Kimura A. Investigation of the therapeutic effects of edaravone, a free radical scavenger, on amyotrophic lateral sclerosis (Phase I/ study). Amyotroph Lateral Scler 2006; 7: 241-245.

7. Nagase M, Yamamoto Y, Miyazaki Y, Yoshino H. Increased oxidative stress in patients with amyotrophic lateral sclerosis and the effect of edaravone administration. Redox Rep 2016; 21:104-112.

8. Aguirre T, Van Den Bosch L, Goetschalckx K, Tilkin P, Mathijs $\mathrm{G}$, Cassiman JJ, et al. Increased sensitivity of fibroblasts from 
amyotrophic lateral sclerosis patients to oxidative stress. Ann Neurol 1998:43:452-457.

9. Sala G, Beretta S, Ceresa C, Mattavelli L, Zoia C, Tremolizzo $\mathrm{L}$, et al. Impairment of g/utamate transport and increased vulnerability to oxidative stress in neuroblastoma SH-SY5Y cells expressing a $\mathrm{Cu}, \mathrm{Zn}$ superoxide dismutase typical of familial amyotrophic lateral sclerosis. Neurochem Int 2005;46:227234.

10. Sala G, Marinig D, Riva C, Arosio A, Stefanoni G, Brighina L, et al. Rotenone down-regulates HSPA8/hsc70 chaperone protein in vitro: a new possible toxic mechanism contributing to Parkinson's disease. Neurotoxicology 2016;54:161-169.

11. Sala G, Trombin F, Mattavelli L, Beretta S, Tremolizzo L, Andreoni $S$, et al. Lack of evidence for oxidative stress in sporadic amyotrophic lateral sclerosis fibroblasts. Neurodegener Dis 2009;6:9-15.

12. Beretta S, Sala G, Mattavelli L, Ceresa C, Casciati A, Ferri A, et al. Mitochondrial dysfunction due to mutant copper/zinc superoxide dismutase associated with amyotrophic lateral sclerosis is reversed by N-acetylcysteine. Neurobiol Dis 2003; 13:213-221.

13. Hardiman O, Al-Chalabi A, Chio A, Corr EM, Logroscino G, Robberecht W, et al. Amyotrophic lateral sclerosis. Nat Rev Dis Primers 2017;3:17085.

14. Tremolizzo L, Sala G, Brighina L, Beretta S, Ferrarese C. Interactions between excitotoxicity and oxidative stress in ALS: clues for pharmacotherapy. In: Murray CA, editor.
Amyotrophic lateral sclerosis: new research. New York:Nova Science Publishers;2005. p.71-109.

15. Bondy SC, LeBel CP. The relationship between excitotoxicity and oxidative stress in the central nervous system. Free Radic Biol Med 1993; 14:633-642.

16. Soon CP, Donnelly PS, Turner BJ, Hung LW, Crouch PJ, Sherratt NA, et al. Diacetylbis(N(4)-methylthiosemicarbazonato) copper(II) (Cull(atsm)) protects against peroxynitrite-induced nitrosative damage and prolongs survival in amyotrophic lateral sclerosis mouse model. I Biol Chem 2011; 286:44035-44044.

17. Bellezza I, Grottelli S, Costanzi E, Scarpelli P, Pigna E, Morozzi G, et al. Peroxynitrite activates the NLRP3 inflammasome cascade in SOD1 (G93A) mouse model of amyotrophic lateral sclerosis. Mol Neurobiol 2018;55:2350-2361.

18. Nakamura T, Lipton SA. 'SNO'-Storms compromise protein activity and mitochondrial metabolism in neurodegenerative disorders. Trends Endocrinol Metab 2017;28:879-892.

19. Hogg MC, Halang L, Woods I, Coughlan KS, Prehn JHM. Riluzole does not improve lifespan or motor function in three ALS mouse models. Amyotroph Lateral Scler Frontotemporal Degener 2018;19:438-445.

20. Ahmadi M, Agah E, Nafissi S, Jaafari MR, Harirchian MH, Sarraf $\mathrm{P}$, et al. Safety and efficacy of nanocurcumin as add-on therapy to riluzole in patients with amyotrophic lateral sclerosis: a pilot randomized clinical trial. Neurotherapeutics 2018;15:430-438. 